\title{
Os desafios do controle interno governamental diante da re- forma do Estado: o caso do Programa de Modernização do Controle Interno do Estado da Paraíba (Promocin)
}

\section{The challenges of governmental internal control before the Reform of the State: The case of the Program of Modernization of The Internal Control of the State of Paraíba - PROMOCIN}

Eudes Moacir Toscano Jr. *

Carla Renata Silva Leitão **

\begin{abstract}
Resumo
Este artigo tem por objetivo desenvolver um estudo comparativo entre as atividades definidas no componente auditoria e controle interno do Programa de Modernização do Controle Interno do Estado da Paraiba (Promocin) - coordenado pela Secretaria do Controle da Despesa Pública (SCDP) - e as diretrizes lançadas pelo processo de reforma do Estado brasileiro para implantação do paradigma da administração pública gerencial no setor público. Esse paradigma aponta para um modelo de gestão do controle interno a posteriori, mais enfocado na avaliação dos resultados da aplicação dos recursos públicos do que no mero cumprimento das formalidades legais aplicáveis às despesas públicas. 0 estudo foi realizado através de levantamentos bibliográficos e documentais acerca do tema, com o intuito de averiguar a consonância entre as atividades contempladas no Promocin e a tendência atual estabelecida pelos ventos da reforma do Estado para o perfil das entidades de auditoria e controle interno da esfera governamental. A pesquisa demonstrou a condição de vanguarda da Secretaria do Controle da Despesa Pública que, através do Promocin, vem procurando estabelecer ações de controle mais efetivas no processo de avaliação dos gastos públicos, possibilitando um considerável salto de qualidade nos serviços de auditoria interna no Poder Executivo estadual.
\end{abstract}

Palavras-chave : Administração Pública Gerencial; Controle Interno; Auditoria Governamental

\begin{abstract}
The present research aims to make a comparative study between the activities defined in the component Auditing and Internal Control of the Program of Modernization of the Internal Control of the State of Paraiba - PROMOCIN, coordinated by the Secretaria do Controle da Despesa Pública, and the defined guidelines launched by the process of Reform of the Brazilian State for implanting the paradigm of the Managerial Public Administration in the Public Sector. The work was carried out through bibliographical and documental approaches concerning the chosen theme, which evidenced the existent compatibility between the mentioned activities carried out by the PROMOCIN, and the international and national current tendency established by the Reform of the State, for the profile of the auditing and internal control entities of the government sphere, which tend to establish a pattern of ex post internal control management, clearly focused on the evaluation of the results of the application of public resources rather than on the mere accomplishment of insufficient bureaucratic formalities, in order to reinforce the efficacy and efficiency in the administration of the public finances.
\end{abstract}

Key Words: Managerial Public Administration; Internal Control; Governmental Auditing

\footnotetext{
- Mestre em Administração Financeira pela Universidade FEderal da Paraíba-UFPB. Auditor de Contas Públicas do Estado da Paraíba - Controladoria Geral do Estado da Paraíba. Endereço: Av.Dep.José Mariz, 1140, apt ${ }^{\circ} .101$ - Tambauzinho - João Pessoa - PB - Brasil - CEP: 58042020... Email: biota@openline.com.br.. - Professora da Universidade Federal da Paraiba. Mestre em Contabilidade pelo Mestrado Multi-institucional UFPB/UFPE/UFRN/UNB. Endereço: R. Sebastião Interaminense, 566 / 204, Bessa, João Pessoa - PB - Brasil - CEP: 58036-300. E-mail: carlaufpb@yahoo.com. 


\section{Introdução}

A administração pública gerencial vem mudando as relações do Estado com a sociedade, e levando a prestação dos serviços públicos a um nível de atendimento, no qual se vislumbra a possibilidade de ser efetivada a verdadeira otimização dos dispêndios públicos.

Dessa forma, iniciativas como o Programa Brasileiro de Administração Fazendária (PNAFE) têm sido vetores de significativas mudanças na estrutura e, principalmente, no processo cultural do serviço público da nação.

O Programa de Modernização do Controle Interno do Estado da Paraíba (Promocin) - que nasceu de um desmembramento do Programa de Modernização da Administração Fazendária (Promafe) da Secretaria Estadual das Finanças - tem como objetivo geral o fortalecimento das ações de controle interno em nível estadual, com a implantação de programas que possibilitem ao governo estadual e à sociedade uma aplicação mais efetiva dos recursos públicos (PARAÍBA, 1999, p.8).

Com o Promocin, a Secretaria do Controle da Despesa Pública da Paraíba busca atingir a excelência na prestação de serviços de auditoria e controle interno dos órgãos da administração pública do Poder Executivo estadual. Para tanto, estabeleceu que seriam necessários:

- qualificação e treinamento do quadro de técnicos e do pessoal de apoio da SCDP, através de programa permanente de capacitação;

- controle efetivo da arrecadação e aplicação dos recursos públicos, nos mais diversos segmentos, através de ferramentas modernas de auditoria interna e administração de recursos humanos e materiais centradas nos princípios constitucionais que devem nortear a administração pública;

- gestão baseada nos princípios de qualidade total.

O Promocin contempla seis componentes que vão desde a aquisição de equipamentos e reforma das instalações físicas da SCDP ao desenvolvimento de sistemas informatizados de controle integrado para gerenciamento estratégico dos recursos públicos. Neste artigo nos deteremos mais especificamente no objetivo auditoria e controle interno, que visa principalmente:

- estabelecer o controle interno como função de Estado;

- fortalecer as ações desse controle no estado da Paraíba e

- atingir a excelência na qualidade dos serviços de auditoria e acompanhamento prestados ao Poder Executivo e à sociedade.

Essas três metas foram desmembradas em atividades cujos objetivos, resumidamente, são:

- otimizar e implementar ações de acompanhamento de programas e projetos, e da dívida pública do estado;

- otimizar e implementar ações de auditoria operacional e de sistema;

- adotar técnicas modernas de auditoria no desenvolvimento dos trabalhos;

- desenvolver e descentralizar o Sistema Integrado de Auditoria e Controle Interno (Siacin);

- redimensionar as atividades dos auditores do Grupo de Análise e Acompanhamento de Licitações (Gaal);

- intensificar a atividade de auditoria de obras públicas e de serviços de engenharia.

Assim, após essa breve apresentação do Promocin, o objetivo desta pesquisa é responder à seguinte indagação: estão as atividades do componente auditoria e controle interno do Promocin em sintonia com o que estabelece o atual paradigma da administração pública para os órgãos de controle governamental? 
Este artigo traz ao conhecimento do público interessado, informações qualitativas sobre a pertinência de programas para modernização da estrutura responsável pela avaliação dos gastos públicos do Estado. Além disso, proporciona mais uma criteriosa contribuição ao parco acervo científico que trata dos aspectos da organização e da gestão dos órgãos de controle interno governamental. Para atingir o objetivo deste estudo, foram feitas pesquisas bibliográfica e documental, que de acordo com Gil (1991, p.48), caracterizam-se, respectivamente, pelo levantamento de dados a partir de material já publicado acerca do tema - como livros, artigos de periódicos e material disponível na Internet - e de materiais que não receberam qualquer tratamento analítico, como, por exemplo, documentos técnicos elaborados por órgãos governamentais. O método utilizado buscou explicitar o tema em estudo e analisá-lo comparativamente ao contexto que se procurou evidenciar.

A pesquisa foi desenvolvida através de um estudo comparativo entre as ações definidas pela SCDP para implantação das quatro primeiras atividades do objetivo auditoria e controle interno do Promocin, quais sejam: 1 . otimizar e implementar ações de acompanhamento dos programas, projetos e da dívida pública do estado; 2. otimizar e implementar ações de auditoria operacional e de sistema; 3. adotar técnicas modernas de auditoria no desenvolvimento dos trabalhos, e 4. desenvolver e descentralizar o Sistema Integrado de Auditoria e Controle Interno (Siacin); e as atuais vertentes para o perfil dos órgãos de controle interno de contas públicas estabelecidas pelo paradigma gerencial, a fim de evidenciar se essas ações estão em conformidade com os requisitos e necessidades da administração pública, a partir do panorama delineado pela bibliografia utilizada na pesquisa sobre o tema.

\section{Contextualização}

\section{Administração pública gerencial}

A administração pública burocrática, em suas mais puras bases weberianas, ${ }^{1}$ buscava cessar os vieses naturais da administração pública patrimonialista que não fazia distinção entre o patrimônio público e o privado.

Em contraposição à administração burocrática, pelo paradigma patrimonialista, a gestão pública era entendida como se o Estado fosse propriedade do rei (BRESSER-PEREIRA, 2001, p.241). Uma frase bastante conhecida do rei Luís XIV resume com absoluta propriedade o espírito do modelo de gestão patrimonialista: " $L$ 'Etat c'est moi!" Dessa perspectiva, não havia como prosperarem as tendências democráticas advindas da fase do capitalismo industrial, que traziam à sociedade valores como a separação entre mercado e Estado e o controle deste a partir da sociedade civil. Segundo Bresser-Pereira (2001, p.241), com o fim do absolutismo monárquico se fez "[...] necessário desenvolver um tipo de administração que partisse não só da clara distinção entre o público e o privado, mas também da separação entre o político e o administrador público.”

Contudo, à medida que o Estado liberal do século XIX dava lugar ao Estado social e econômico do século XX, verificou-se que a administração pública burocrática apresentava sérios limitadores em termos de qualidade, eficiência e economia. Bresser-Pereira enfatiza que "na verdade, a administração burocrática é lenta, cara, autoreferida, pouco ou nada orientada para o atendimento das demandas dos cidadãos". (BRESSER-PEREIRA, 2001, p.241). Segundo Ribeiro (1997.p.4), "tendo cumprido o seu papel no passado, o modelo burocrático torna-se obsoleto por seu caráter excessivamente formalista e rígido, hierarquizado e pouco comprometido com resultados."

A administração pública gerencial surgiu, então, como mais uma alternativa ao processo evolutivo da organização do Estado, na busca pela eficiência e pela eficácia na aplicação regular dos recursos públicos. Conforme explicita Ribeiro (1997, p.17), as mais visíveis vantagens da administração pública gerencial são a flexibilidade, a criatividade, o incentivo às inovações, a orientação para a obtenção de resultados, a avaliação de resultados através de indicadores de desempenho e a autonomia na gestão, com o controle de resultados a posteriori.

${ }^{1}$ Relativas às idéias do sociólogo e economista alemão Max Weber, grande teórico da burocracia. 
Ainda a esse respeito, Osborne e Gaebler (apud CATELLI et al, 2001, p.3) enfatizam que: "ao contrário da administração burocrática, fixada nos controles formais, que se concentra excessivamente sobre as entradas dos recursos, a gestão empreendedora enfatiza o controle sobre as saídas, os resultados."

Ainda que houvesse surgido como uma forma de diminuir os efeitos da corrupção, do nepotismo e do empreguismo, características do paradigma patrimonialista, a administração pública burocrática não primava pelo empreendedorismo; isto é, não trazia em seu arcabouço teórico, linhas filosóficas que delineassem a possibilidade de que o modelo, na sua aplicação, vislumbrasse a ação de medidas autônomas dos recursos humanos, no intuito de atingir as metas estratégicas da administração pública. Catelli (2001, p.3) afirma que: "[...] a burocracia estatal tende a perpetuar-se e a constituir um fim em si mesma, fixando-se em procedimentos formalistas de controle que geram ineficiência."

As críticas ao modelo burocrático da administração pública brasileira, têm sido, ao longo das últimas décadas, motivadoras de várias tentativas de superação de sua inerente rigidez processual. Já em 1967, através do Decreto-lei $\mathrm{n}^{\mathrm{0}} 200$, foi instituída a descentralização funcional via transferência de atividades do Estado para autarquias, fundações, empresas públicas e sociedades de economia mista, com vistas a aumentar a eficiência operacional na condução das ações à sociedade (RIBEIRO, 1997, p.17). Posteriormente, em 1970, a criação da Secretaria de Modernização (Semor), e mais recentemente, em 1981, o Programa Nacional de Desburocratização (PrND), foram também marcos da jornada da administração pública brasileira em busca de processos mais eficientes de gestão.

O relativo insucesso dessas tentativas de modernização do Estado decorreu, em boa parte, de uma crença inglória de que para mudar a dinâmica administrativa da iniciativa pública, bastaria apenas criar mecanismos legais (leis, decretos e portarias) que determinassem a alteração do status quo da administração pública. Para verdadeiramente atender aos objetivos contemporâneos da reforma do Estado, há que se fazer muito mais do que simplesmente obter aprovações de leis no Congresso. A redefinição do Estado não consiste apenas num ato, mas sim num processo (CARDOSO, 2001, p.16).

O atual Plano Diretor da Reforma do Aparelho de Estado Brasileiro propõe-se implantar no setor público as mudanças de valores e comportamentos preconizados pelo paradigma da administração gerencial, além de viabilizar a revisão dos processos públicos, almejando maior eficiência, através da filosofia da qualidade aplicada à boa gestão dos recursos públicos (FALCÃO e ABE, 1997, p.7).

\section{Paradigmas atuais do controle interno governamental - o Estado gerencial e o governo por resultados}

\section{$O$ controle interno da administração pública}

O controle interno governamental efetiva-se através do estabelecimento de mecanismos de controle dos processos de gestão.

Na visão de Silva (1999, p.1), "os mecanismos de controle representam o elemento essencial para assegurar que o governo atinja os objetivos estabelecidos nos programas de longa duração com eficiência, efetividade e dentro dos preceitos legais da ordem democrática".

Essencialmente formalista, policialesco e com visão limitada ao aspecto contábil - ou seja, apenas ao fiel cumprimento dos registros financeiros dos eventos -, o controle governamental, durante toda a fase burocrática, tinha se tornado incapaz de atender ao clamor da sociedade organizada quanto à prestação de contas da gerência do dinheiro público. A respeito das limitações do controle governamental brasileiro, Ribeiro (1997, p.11) afirma que apesar de todo o progresso verificado na estrutura institucional dessa função do Estado, até a década de 1960 , "[...] a prestação de contas limitava-se ao aspecto formal: apresentação de comprovante de gastos efetuados, sem a comprovação da efetiva realização das despesas."

De uma perspectiva técnica, Silva $(1999$, p.12) identifica cinco objetivos estratégicos para os sistemas de controle nas organizações públicas: 
- proteger os ativos dos erros intencionais (ou não) e também das irregularidades;

- obter informações corretas e seguras para subsidiar o processo decisório;

- conseguir adesão às políticas gerais da organização;

- atingir as metas e programas da organização;

- promover a eficiência e a eficácia nas operações da organização, pela utilização racional dos recursos disponíveis.

A administração pública burocrática, devido à sua visão estrita sobre os processos, deixava de analisar o desempenho das organizações sob o aspecto do alcance das metas e dos resultados dos programas. Da perspectiva de Piscitelli (apud RIBEIRO, 1997, p.8), o sistema de controle da administração pública tem se reduzido basicamente a verificar se os processos estão de acordo com a legislação aplicável, deixando de lado a análise de aspectos como a eficiência e a eficácia dos dispêndios públicos.

O contexto atual aponta para a construção de uma estrutura de controle mais participativa, que deixa de enfatizar apenas o controle da formalidade dos atos administrativos e passa a focar o controle dos resultados da gestão pública. Nessa nova tendência, a sociedade passa a exercer um controle paralelo da efetividade dos gastos públicos e dá o primeiro passo em busca da consolidação do controle social (SILVA, 1999, p.47).

\section{Controle social e accountability}

De acordo com (RIBEIRO, 1997, p.5), o conceito de accountability, ainda inexistente na cultura política brasileira e na língua portuguesa, se notabiliza pela "[...] prestação de contas do gestor para além dos limites formais da burocracia, responsabilizando-o perante a sociedade contra excessos de poder."

Silva (1999, p.50), enfatiza que o conceito de accountability é fundamental para o aperfeiçoamento das democracias. O autor explica que em países menos desenvolvidos, como o Brasil, o exercício da democracia fica limitado à aceitação passiva do domínio do Estado, o que se reflete na negação do direito à educação básica gratuita para todos e até mesmo do salário mínimo para os trabalhadores.

Numa realidade onde se discute a cristalização de uma legislação a partir de considerações do tipo "lei que pega e que não pega", O’Donnel (apud SILVA, 1999, p.54), explicita que para o estabelecimento do grau de accountability nas sociedades latino-americanas, há que se derrubar verdadeiras tendências patrimonialistas que se configuram nas "[...] falhas na legislação existente, inefetividade na aplicação da lei, dificuldades na relação da burocracia com os cidadãos comuns, inacessibilidade ao Judiciário e a processos justos e, ainda, a ilegalidade pura e simples."

Apesar de bem estruturado no âmbito legal, o controle governamental ainda prescinde de uma ação mais proativa, com vistas ao cumprimento integral da expectativa criada a partir de suas bases institucionais pela Carta Magna.

Fruto de um movimento global acerca da gestão dos gastos governamentais, a necessidade de procedimentos que traduzam com maior confiança a transparência na prestação de contas dos gestores públicos tem seguido uma lógica bastante linear em vários países do mundo (DIAMOND, 2002, p.4). De acordo com Diamond, organizações internacionais como a Organização Internacional de Entidades de Fiscalização Superiores (Intosai) vêm, ao longo dos anos, desenvolvendo padrões de estruturas e processos de controle interno calcados na eficiência e na efetividade, com vistas a garantir a transparência no controle dos resultados dos dispêndios públicos.

Assim, os sistemas de controle interno, que no paradigma burocrático, segundo Silva (1999, p.62), não são suficientes para garantir que o serviço público sirva sua clientela de acordo com os padrões normativos do governo democrático, precisam agora criar indicadores de performance para:

- aferir o desempenho das organizações públicas; 
- gerenciar estrategicamente seus recursos de modo a otimizar as ações do controle governamental;

- desenvolver sistemas de informações gerenciais que possibilitem a utilização dos registros contábeis como elementos que dêem embasamento às decisões dos gestores públicos; $\mathrm{e}$

- criar mecanismos eficientes de comunicação com a sociedade, a fim de consolidar o controle social, a partir de um gestão governamental transparente.

Esses são os principais desafios para que a Secretaria do Controle da Despesa Pública do Estado da Paraíba se converta num organismo eficiente de avaliação e de controle da aplicação dos dispêndios públicos.

\section{Avaliando o resultado da gestão pública}

De acordo com Falcão e Abe (1997, p.30), o Programa Brasileiro de Qualidade e Participação na Administração Pública é baseado na filosofia de que para haver ganho de eficiência, eficácia e qualidade, os serviços devem focar em três dimensões:

- na promoção - que é definida como a vontade política da liderança (alta administração) de comprometer-se com a consecução de resultados positivos;

- no sistema - que aborda todos os elementos da gestão interna, como gestão de processos, desenvolvimento e gestão de recursos humanos, planejamento estratégico e informação e análise; e

- na meta - que se refere ao alcance de objetivos institucionais, ao desempenho final da organização, pelo cumprimento de sua missão institucional.

Nesta dimensão destacam-se dois elementos: os resultados institucionais e o foco no cliente e em sua atenção. Com relação a essa ruptura com o modelo de avaliação característico da administração burocrática, Falcão e Abe (1997, p.37) afirmam que de nada ou quase nada adianta uma gestão irreparável do ponto de vista do cumprimento de todas as normas exigidas, se o resultado de sua ação concreta é pífia, nulo ou desprezível no que concerne ao atendimento do cidadão e na resposta às suas demandas e necessidades.

Para que essa nova ordem se estabeleça definitivamente, a definição e a padronização de indicadores de desempenho assumem importância estratégica, a fim de que se possa avaliar a eficácia, a eficiência e a efetividade da gestão pública. Entretanto, na iniciativa pública as noções de lucro, prejuízos, ganho e perda não se prestam como parâmetros de resultado. A administração pública procura propiciar aos seus stakeholders ${ }^{2}$ (a sociedade), benefícios que devem ter valor econômico maior do que o custo financeiro derivado dos tributos cobrados para financiar os gastos da gestão pública.

Nota-se a complexidade do processo de criação de indicadores de desempenho da gestão pública, quando deixamos de tratar com conceitos meramente financeiros e passamos a raciocinar em termos econômicos. Dessa forma, o desenvolvimento de sistemas contábeis gerenciais que permitam fornecer informações úteis no processo decisório é fundamental para a elaboração e monitoramento de indicadores de performance, a fim de viabilizar a mensuração do desempenho da gestão pública.

Em recente trabalho sobre a necessidade de reestruturação dos sistemas de controle interno das administrações públicas, visando tornar a função de auditoria interna mais efetiva, o Fundo Monetário Internacional (FMI) recomenda (DIAMOND, 2002, p.19):

- desenvolver visões estratégicas quanto à auditoria interna na estrutura administrativa das finanças públicas, cobrindo não apenas as auditorias de conformidade e de regularidade, mas também assumindo um papel mais abrangente para garantir a eficiência no controle dos gastos públicos;

- reestruturar as práticas de auditoria, a fim de redirecionar as verificações ex ante das despesas públicas para práticas mais aplicáveis a auditorias de sistemas e outras;

${ }^{2}$ Da etimologia do universo das finanças, são assim chamados os interessados nos investimentos. 
- revisar a função de auditoria interna e o seu staff, além de redesenhar a estrutura organizacional e suas responsabilidades;

- preparar manuais baseados na nova visão de auditoria interna e nos respectivos programas de melhoria;

- baseado nos manuais, definir um programa de treinamento para os auditores internos se desenvolverem conforme essa nova perspectiva;

- desenvolver um programa de recrutamento e desenvolvimento do corpo técnico para o serviço de auditoria interna; e

- fomentar o envolvimento da auditoria interna no desenvolvimento de novos sistemas de gerência contábil e financeira, para garantir que mecanismos adequados de controle interno sejam considerados nesses sistemas.

De acordo com esse paradigma, a auditoria governamental passa a exercer um papel enfocado numa avaliação abrangente dos controles internos, com mais ênfase em controles gerenciais, deixando de lado a função de mero avaliador da conformidade legal das despesas públicas (DIAMOND, 2002).

Para a Secretaria do Controle da Despesa Pública, uma eficiente avaliação da gestão pública implica obrigatoriamente a necessidade de redefinição do seu processo de planejamento das auditorias, pela implantação de uma metodologia para as auditorias operacionais. Implica igualmente a criação de um sistema de informações gerenciais que otimize a análise do desempenho da gestão pública e possibilite fornecer dados estratégicos para melhor subsidiar os administradores em suas decisões, servindo também de base para o fomento à consolidação do controle social no estado da Paraíba.

\section{Principais metas do Promocin para atingir a efetividade na gestão das ações de controle interno das contas públicas}

\section{Planejamento estratégico de auditorias com base na gestão de riscos}

A gestão dos riscos é um tema de grande relevância nos processos de planejamento de auditorias e de implantação de controles internos.

De acordo com as recomendações do Departamento de Auditoria Interna do Condado de Orange, no estado da Califórnia (EUA), dirigidas aos administradores públicos de sua jurisdição, o tema central dos controles internos é: ${ }^{3}$ a identificação de riscos ao alcance dos objetivos de uma organização e a ação para gerenciar esses ris$\cos$.

Assim, se considerarmos que o fluxo de ingresso e saída de bens, serviços e recursos financeiros do patrimônio do Estado é de relevante magnitude - e que os meios à disposição dos órgãos de controle interno governamental para fiscalizá-los são escassos - torna-se necessário para esses órgãos buscar mecanismos que viabilizem a alocação eficiente dos parcos recursos de que dispõem, para otimizarem os resultados que podem ser alcançados no exercício de sua missão constitucional de controlar a execução orçamentária.

A conceituação de risco para o processo de planejamento das auditorias pode ser explicitada como a:

“[...] capacidade de avaliação do potencial de perda, oriundo da probabilidade de ocorrência de erro, ineficiência, ineficácia, gestão antieconômica, ilegalidade, desvio de objetivos estratégicos, táticos e operacionais, e ainda de ocorrências que exijam a ação coordenada do controle interno conforme suas atribuições regimentais." (FALCÃO et al, 1997, p.7).

3 "A questão central do controle interno é (1) identificar os riscos a serem enfrentados para se atingir os objetivos da organização e (2) fazer o que é necessário para gerir tais riscos. Assim, estabelecer metas e objetivos é precondição para o controle interno. Se uma organização não tem metas nem objetivos, não há necessidade de controle interno."(COUNTY OF ORANGE, 2003, P.11). 
O processo de planejamento anual utilizado pela SCDP para auditar os diversos ciclos da gestão dos recursos públicos necessitava ser desenvolvido de forma mais estratégica, para que se tornasse uma ferramenta verdadeiramente gerencial, e não apenas uma peça burocrática de efeito meramente formal.

O Promocin havia detectado essa necessidade, e assim contemplou em uma das atividades previstas para o objetivo auditoria e controle interno, a contratação de uma consultoria para redesenhar os processos de auditoria da Secretaria do Controle da Despesa Pública, com vistas a desenvolver uma metodologia padronizada para o planejamento das auditorias de rotina, que possibilitasse a otimização dos recursos financeiros e humanos, alocando-os da forma mais eficiente possível.

A metodologia em questão consiste na determinação do universo dos órgãos públicos que devem ser auditados pela SCDP, seguida pela identificação de todos os ciclos transacionais que compõem cada um dos órgãos a serem auditados. Após essa identificação, é feito um ordenamento dos ciclos, pelo grau de impacto que eles representam nas organizações. Em seguida, essas informações são lançadas numa planilha eletrônica, onde junto com outras variáveis - como o período decorrido desde a última auditoria realizada no ciclo, a complexidade do ambiente de controle da organização, a administração e os controles internos do ciclo, além do grau de adesão à normas internas e legislações aplicáveis - serão efetuados os cálculos matemáticos que definirão as prioridades para o programa de auditorias operacionais do exercício financeiro.

Com semelhante metodologia, a Secretaria Federal de Controle (SFC) - hoje, órgão componente da estrutura da Controladoria Geral da União -, também realiza o seu planejamento estratégico para determinação de uma ordem decrescente de exposição ao risco para os órgãos e ciclos operacionais, que serve de base ao processo que dá prioridade à sua programação de auditorias operacionais (FALCÃO et al, 1997, p.6).

\section{Avaliação e auditoria de desempenho}

\section{A auditoria de desempenho}

O Tribunal de Contas da União (TCU) assim a define: "a auditoria de desempenho consiste na avaliação sistemática dos programas, projetos e atividades governamentais, assim como dos órgãos e entidades jurisdicionadas ao Tribunal.'(BARROS, 2000, p.1). A egrégia corte de contas federal delimita dois campos de ação para a auditoria de desempenho: a auditoria operacional e a avaliação de programas (BARROS, 2000, p.1). O TCU especifica que quanto aos aspectos que envolvem economia, eficiência e eficácia, aplicam-se a auditoria operacional; no que se refere à efetividade, a avaliação de programas, que objetiva examinar o impacto nos programas, projetos e atividades governamentais (BARROS, 2000, p.2).

De acordo com Oliveira (2003, p.6), os conceitos de eficiência, eficácia, economicidade e efetividade constituem e/ou consubstanciam os principais objetivos da auditoria operacional.

Assim, conforme estabelece o autor, a auditoria de desempenho (ou operacional) divide-se em três áreas principais:

- auditoria de eficiência e economicidade - que, ainda segundo o autor, se propõe a analisar se as entidades estão adquirindo os materiais ou serviços de que efetivamente necessitam com qualidade e na quantidade adequada (e ao menor custo possível), se cumprem as disposições legais e regulamentares cuja inobservância possa afetar significativamente a aquisição, salvaguarda e o uso dos recursos - e, ainda, se utilizam um sistema de controle adequado para medir o seu desempenho, em termos de economia e eficiência dos programas (OLIVEIRA, 2003, p.8);

- auditoria de eficácia - que objetiva medir o grau dos resultados ou benefícios alcançados em determinado programa, ou ainda, objetiva verificar se a administração, através de um projeto ou meta, conseguiu atingir os objetivos a que se propôs, inclusive os estabelecidos pelas normas pertinentes. Um viés apontado pelo autor é o de que muitas entidades não dispõem de sistemas estruturados para coletas de dados que propiciem a adequada avaliação do desempenho. Como resultados práticos desse tipo de auditoria, podem ser apontados possíveis ganhos em desempenho da entidade e o aprimoramento dos 
procedimentos e dos controles administrativos; ou seja, o processo de gestão em seus múltiplos aspectos de planejamento, execução, controle e avaliação;

- auditoria de efetividade - que visa mensurar o efeito ou impacto transformador de uma ação que quer se modificar. Nesse enfoque de auditoria operacional, é fundamental examinar três dimensões básicas:

- a primeira diz respeito à adequação, em que é verificado se os resultados apresentados correspondem às necessidades que deram origem à ação;

- a segunda é da eqüidade, que implica verificar se a ação implementada e os resultados permitiram uma distribuição mais justa dos recursos e dos benefícios;

- a terceira refere-se à propriedade política, ou seja, verificar se as exigências e demandas da sociedade foram atendidas (OLIVEIRA, 2003, p.10).

De acordo com Barros (2000, p.3), "a auditoria, em qualquer de suas vertentes, compreende as seguintes macroetapas: planejamento, obtenção e análise de evidências, preparação e divulgação de relatórios". Entretanto, não obstante a importância de todas as fases no processo de auditagem, na auditoria operacional a fase de planejamento torna-se mais relevante em virtude da necessidade de se determinar o alcance da auditoria, seus objetivos, critérios, recursos necessários, a formação de equipe com especialistas em diversas áreas etc., para que se possa assegurar que a auditoria abranja os aspectos de maior impacto na entidade auditada (OLIVEIRA, 1996, p.24).

Vale ressaltar o benefício extra que a aplicação de programas de auditoria de desempenho agrega aos serviços prestados pelos órgãos de controle. A avaliação da gestão por meio da auditoria com enfoques gerenciais pode ser mais um instrumento de trabalho utilizado nos controles interno e externo. Esse processo é incorporado ao cabedal de conhecimentos de técnicas de controle desses órgãos, e sua aplicação não implica a substituição de quaisquer das técnicas que já amplamente utilizadas para avaliação da gestão pública (FALCÃO e ABE, 1997, p.32).

Atenta a essa tendência da moderna auditoria pública, a Secretaria do Controle da Despesa Pública viabilizou, através do Promocin - e da contratação da Trevisan Auditores Associados para dar consultoria na área de auditoria e controle interno - uma metodologia para a execução de auditorias operacionais, com vistas a avaliar e corrigir a eficiência e a eficácia dos sistemas de controle interno das entidades administrativas do estado da Paraíba, e mensurar a efetividade dos seus programas de governo.

\section{Controladoria e sistemas de informações gerenciais}

Característica marcante do paradigma burocrático da administração pública, a ênfase na formalidade também se estendeu aos modelos dos sistemas de registros da contabilidade pública.

Da perspectiva do paradigma burocrático, as atividades de controle interno da administração pública estavam mais voltadas para o atendimento formal aos órgãos de fiscalização externa do que para a avaliação da forma como os administradores atuavam na prestação dos serviços públicos (SILVA, 2002, p.205).

A necessidade de utilização das informações contábeis como elementos que proporcionassem maior segurança na tomada de decisões, trouxeram ao cenário atual das organizações, públicas ou privadas, as vantagens da aplicação da contabilidade gerencial. Uma contabilidade essencialmente multidisciplinar, abrangendo a economia, a estatística e a administração, que propicia não apenas o registro dos fatos contábeis, mas que também permite que seja gerada uma série de informações que criam condições para que as organizações se desenvolvam de maneira estratégica.

A contabilidade, como ciência, tem uma rica base conceitual da qual devemos nos valer e, interagindo de forma multidisciplinar com os demais ramos do conhecimento, buscar a construção de uma via alternativa à contabilidade tradicional, cuja base conceitual é inadequada para modelar as informações destinadas ao uso dos gestores (ALMEIDA et al, 2001, p.343). Assim, nasce a controladoria, a qual, segundo esses autores, pode ser entendida 
como a estrutura da organização que estabelece as bases teóricas e conceituais necessárias à modelagem, construção e manutenção de sistemas de informações e modelo de gestão econômica que supram as necessidades de informação dos gestores, induzindo-os, quando solicitarem, a tomarem as decisões mais adequadas (ALMEIDA et al, 2001, p.344).

Ainda quanto a essa questão, vale ressaltar as observações de Heckert e Wilson (apud BEUREN, 2002, p.22) que atribuem duas funções básicas à controladoria:

- a supervisão da contabilidade geral, da contabilidade de custos, da auditoria, dos impostos, dos seguros e das estatísticas; e

- as aplicações da função contábil na resolução de futuros problemas administrativos.

Apesar de ter mais de 20 anos de existência, a Secretaria do Controle da Despesa Pública da Paraíba - que, de acordo com o Decreto estadual no 14.855 de 26-10-1992, é o órgão central da auditoria do sistema de controle interno do Poder Executivo - ainda se ressente de uma estrutura institucional que lhe dê uma dimensão estratégica nos moldes de uma controladoria.

De fato, pode-se constatar que a SCDP atua predominantemente na área de auditoria, sem que, entretanto, haja maiores preocupações com a gerência de sistemas de informações sobre custos e/ou sobre estatísticas da aplicação dos recursos públicos. Acredita-se que o fato de ter originalmente nascido como um pequeno grupo de auditagem dentro da estrutura organizacional da Secretaria das Finanças do Estado da Paraíba, bem como a tendência dantesca do Estado de definir reformas apenas modificando estruturas legais e não funcionais, tenham levado a atual Secretaria do Controle a passar essas mais de duas décadas sempre mudando de nome e de atribuições, sem alcançar a efetiva correspondência entre as citadas atribuições legais a ela incumbidas pelos legisladores e as atividades que vem efetivamente desempenhando ao longo desses anos.

À luz dos estudos de Silva (2002), a Secretaria do Controle da Despesa Pública está estruturada no âmbito da organização do sistema de controle interno do estado de forma integrada. De direito, ela não se subordina a nenhuma outra secretaria de estado, estando apenas subordinada ao Gabinete da Governadoria. Todavia, reiteramos que a SCDP ainda não exerce na sua plenitude todas as ações que estão previstas nos seus normativos institucionais, atuando de fato, mais enfaticamente, como uma auditoria interna do Poder Executivo. Estruturalmente, a SCDP está em posição privilegiada com relação ao seu status de órgão fiscalizador da aplicação dos recursos do estado, mas operacionalmente ainda não se identificou como um órgão de gerenciamento e assessoramento estratégico do estado. No Brasil, a estrutura dos sistemas de controle governamental, na maioria das vezes, é meramente formal e distante dos fatos e das pessoas a serem fiscalizadas e controladas, pois costuma ser implantada de modo casuístico e ornamental, sem qualquer embasamento técnico (SILVA, 1995, p.32).

Para atingir o patamar de órgão de excelência na condução dos processos de controle e de auditoria dos recursos à disposição do estado, a Secretaria do Controle carece desenvolver uma estrutura que permita a junção de três sistemas:

- sistema de registro contábil;

- sistema de auditoria interna;

- sistema de coleta e gerenciamento de custos.

Segundo Silva (2002, p.209), para que o sistema de controle interno preconizado pela Constituição de 1988 possa ser considerado implementado é necessário que o órgão central de controle, ou controladoria, englobe as funções de contabilidade e de auditoria. Um sistema de controle montado nesses moldes apresenta mais condições de gradualmente redirecionar suas ações, saindo do exame das formalidades para uma perspectiva proativa, em que relatórios gerenciais sobre economicidade, eficiência e eficácia podem ser gerados a partir da integração dessas duas funções. 
O Sistema Integrado de Auditoria e Controle Interno (Siacin), previsto no objetivo específico auditoria e controle interno do Promocin, tem como algumas de suas principais atividades:

- estruturar e integrar banco de dados com informações gerenciais sobre o governo na SCDP;

- acessar e tratar dados sobre a criação, estrutura, quadro de pessoal e gestão das entidades e fundos especiais do governo;

- implementar e manter a integração com os mais variados sistemas de informações gerenciais dos três níveis de governo;

- disponibilizar acesso direto ao Siacin ao chefe do Poder Executivo estadual.

Juntamente com o Programa Paraíba de Qualidade e Controle Total (Propacto) - que se configura como um grande banco de informações sobre os custos praticados na administração pública estadual - e o Sistema Integrado de Administração Financeira (Siaf), o Siacin pretende se consolidar como sistema de informações gerenciais do governo do estado, tornando a função da Secretaria do Controle da Despesa Pública mais próxima daquela delineada na Constituição para os órgãos gestores dos sistemas de controle interno governamentais.

O Siacin terá como desafio principal a missão de capturar os registros contábeis efetuados no Siaf e os dados referentes aos custos da administração pública monitorados pelo Propacto e transformá-los em:

- informações gerenciais que auxiliem os gestores públicos ao tomarem decisões;

- estudos estatísticos que tracem perfis e tendências dos gastos públicos;

- informações em formato mais inteligível para viabilizar a participação da sociedade na efetivação do controle social.

Estabelecendo as diretrizes da Controladoria como perfil para a prestação dos serviços públicos de gerência dos processos de controle interno e de auditoria, a Secretaria do Controle estará essencialmente deixando de lado os excessos do formalismo burocrático, para atuar de forma gerencial, avaliando o desempenho da administração através de auditorias operacionais, revisando operações e avaliando-as pelos aspectos da economia, eficiência e eficácia, possibilitando ao governo conhecer o grau de atendimento às demandas sociais no que se refere às políticas de educação, segurança, saúde, justiça etc.

\section{Considerações finais}

À medida que o paradigma gerencial vai se consolidando como viga mestra da administração pública contemporânea, aumenta a sua responsabilidade de convencer a sociedade (os investidores públicos) de que a dinâmica dessa nova filosofia administrativa não é apenas mais um modismo. É vital que sejam criados mecanismos de aferição dos investimentos públicos, para traduzir com maior clareza e objetividade a retórica política dos administradores públicos.

Assim, ferramentas como a auditoria de desempenho, o planejamento estratégico baseado na gestão dos riscos e dos impactos e os sistemas integrados de informações gerenciais - que buscam principalmente avaliar o nível de excelência das organizações públicas, a partir de aspectos como eficácia, eficiência, economicidade e efetividade - surgem para concretizar vertentes como a gestão de riscos, accountability, integração dos órgãos de controle e a transparência da gestão pública, da perspectiva da construção de uma sociedade mais socioeconomicamente equilibrada.

De acordo com estudos do FMI, a demanda pela accountability dos gestores públicos e por transparência nas ações dos governos têm resultado numa generalizada exigência por mais informações acerca dos serviços e dos programas de governo (DIAMOND, 2002, p.4). Assim, em parcerias com organismos internacionais como a Organização Internacional de Instituições Superiores de Auditoria (Intosai), o FMI vem recomendando aos paí- 
ses chamados emergentes uma série de medidas para fortalecer as funções das auditorias internas de seus sistemas de serviços públicos (DIAMOND, 2002, p.18). Das recomendações do FMI, o citado autor destaca que:

- as atividades de auditoria interna, embora incluam operações tradicionais de verificação de conformidade e de regularidade, também devem incluir auditorias de sistemas, operacionais e de tecnologia da informação;

- para funcionar efetivamente, a auditoria interna deve ficar estrategicamente afastada da execução das rotinas administrativas da organização, subordinando-se apenas à alta administração, para garantir o resultado das suas orientações;

- a auditoria interna deve utilizar procedimentos de auditoria internacionalmente reconhecidos por entidades de representação;

- a auditoria interna deve estar colocada como componente central do sistema de controle interno financeiro, a fim de resguardar os interesses financeiros do governo.

É oportuno que se ressalte a importância das atividades previstas no componente auditoria e controle interno do Promocin, que viabilizarão a adequação da função auditoria interna do governo do estado da Paraíba ao atual paradigma da administração pública, e possibilitarão ao setor público desse estado a concretização de uma filosofia gerencial eficaz e eficiente, do ponto de vista do alcance dos objetivos estratégicos do estado, e responsavelmente efetiva, uma vez que proporcionará aos cidadãos paraibanos a oportunidade de realizarem, através da transparência, um controle social da aplicação dos recursos públicos postos sob responsabilidade do Poder Executivo estadual.

Adiante, apresentamos um quadro-resumo correlacionando as principais atividades do componente auditoria e controle interno do Promocin com as tendências estabelecidas pela administração gerencial, contrapondo-as com as ineficiências da administração burocrática. 


\section{Correlação entre o Promocin e o paradigma estabelecido pela administração gerencial para o controle interno governamental}

\section{ADMINISTRAÇÃOO BUROCRÁTICA}

Controle formal e a priori de processos com auditorias de conformidade e de regularidade

Estrutura organizacional do órgão de controle interno voltada exclusivamente para a realização de auditorias internas

Planejamento meramente para efeito de cumprimento normativo e sem indicadores de desempenho

Enfoque na contabilidade financeira para cumprimento de dispositivos legais

\section{ADMINISTRAÇÃO GERENCIAL}

Controle de resultados a posteriori, enfoque na eficácia, na eficiência e na efetividade

Estrutura organizacional do órgão de

controle interno contemplando as

funções de contabilidade, auditoria e gestão de custos

Planejamento como ferramenta

estratégica para a otimização dos recursos e alcance das metas organizacionais

Abordagem sistêmica através da contabilidade gerencial, para facilitar a tomada de decisão

Auditorias nos processos e com ações corretivas e preventivas baseadas em gestão proativa
AÇÕES DO PROMOCIN PARA EFETIVAR A ADMINISTRAÇÃO GERENCIAL NO CONTROLE INTERNO GOVERNAMENTAL

Padronização de processo de auditoria de desempenho (operacional e de programas de governo)

Estruturação do órgão de controle interno nas bases de uma controladoria, com o desenvolvimento do Sistema Integrado de Auditoria e Controle Interno (Siacin) Implantação do planejamento estratégico das auditorias de desempenho com base na gestão dos riscos

Estruturação do órgão de controle interno nas bases de uma controladoria, com o desenvolvimento do Sistema Integrado de Auditoria e Controle Interno (Siacin)

Auditorias com ênfase em correções dos produtos e com ações corretivas baseadas em ações reativas
Padronização do processo de auditoria de desempenho (operacional e de programas de governo)

Fonte: Secretaria do Controle da Despesa Pública (2004).

Hoje, mais do que nunca, quando se vive uma limitação de recursos financeiros cada vez maior e uma crescente necessidade de melhores resultados na aplicação do dinheiro público em saúde, educação e segurança, há uma desesperada exigência por respostas mais eficazes no que diz respeito ao retorno dos investimentos públicos. Os gestores públicos, legisladores e cidadãos querem e precisam saber se os recursos públicos estão sendo administrados adequadamente e em cumprimento aos preceitos legais. Querem saber também se os programas conduzidos pelas organizações governamentais estão atingindo os objetivos propostos e se as operações estão sendo econômicas e eficientes (FALCÃO e ABE, 1997, p.36):

Os órgãos de controle interno governamental precisam demonstrar à sociedade que o papel desenvolvido por eles corresponde de alguma forma às suas expectativas. Numa nova filosofia de busca por resultados, esses órgãos que são incumbidos de aferir os resultados das ações praticadas pela administração pública, carecem mais do que qualquer outra entidade, apresentar resultados eficientes. A implementação das alternativas discutidas neste estudo na SCDP possibilitará atingir esses resultados e trará à Paraíba, a perspectiva de uma administração pública mais responsável e amplamente focada na melhoria contínua dos processos de otimização do desempenho, do gerenciamento dos custos e da qualidade dos serviços prestados ao cidadão. 


\section{Referências}

ALMEIDA, L. B. et al. Controladoria. In: CATELLI, A. (Org.). Controladoria: uma abordagem da gestão econômica - Gecon. 2. ed. São Paulo: Atlas, 2001.

BARROS, E. F. Auditoria de desempenho e auditoria contábil: principais aspectos metodológicos da etapa de planejamento. In: CONGRESSO BRASILEIRO DE CONTABILIDADE, 16., 2000, Goiânia. Disponivel em: <www.redecontabil.com.br/artigo/arquivos/art_02.pdf>. Acesso em: 5 jul. 2003.

BEUREN, I. M. 0 papel da controladoria no processo de gestão. In: SCHMIDT, P. (Org.). Controladoria agregando valor para a empresa. Porto Alegre: Bookman, 2002.

BRESSER-PEREIRA, L. C. Da administração pública burocrática à gerencial. In: BRESSER-PEREIRA, L. C.; SPINK, P. (Org.). Reforma do Estado e administração pública gerencial. 4. ed. Rio de Janeiro. Editora FGV, 2001.

CARDOSO, F. H. Reforma do Estado. In: BRESSER-PEREIRA, L. C.; SPINK, P. (Org.). Reforma do Estado e administração pública gerencial. 4. ed. Rio de Janeiro. Editora FGV, 2001.

CATELLI, A. et al. Gestão Econômica de Organizações Governamentais. In: CONGRESSO DO INSTITUTO INTERNACIONAL DE CUSTOS, 7. 2001, León. Disponivel em: <www.gecon.com.br/down_artigos.asp>. Acesso em: 5 jul. 2003

COUNTY OF ORANGE. Internal Auditing Department. Understanding internal controls. Disponivel em: $<$ <ttp://www.oc.ca.gov/audit/documents/understanding_ic.pdf>. Acesso em: 15 jan. 2003.

DIAMOND, J. The role of internal audit in government financial management: an international perspective. Washington: IMF, 2002. 35p. Disponivel em: <www.imf.org/external/pubs/ft/wp/2002/wp0294.pdf>. Acesso em: 20 maio 2003. (Working paper).

FALCÃO, M.; ABE, S. Qualidade e participação na administração pública federal - novos critérios para a avaliação da gestão pública. Brasília, DF, 1997. Disponivel em: <www.tcu.gov.br/isc/sedip/premioscorrea/monografia.97.pdf>. Acesso em: 5 jul. 2003.

et al. SISTEMA INTEGRADO DE ANÁLISE DE RISCO (SIAR) - uma ferramenta gerencial para a priorização de atividades e otimização da distribuição de pessoal da Secretaria Federal de Controle. Brasília, DF, 1997. Disponível em: <www.stn.fazenda.gov.br/premio_TN/conteudo_mono_pr2_tema3.html>. Acesso em: 20 set. 2003.

GIL, A. C. Como elaborar projetos de pesquisa. 3. ed. São Paulo: Atlas, 1991.

OLIVEIRA, A. M. Controle e auditoria governamental com enfoque em auditoria operacional. Brasilia, DF, 1996. Disponivel em: <www.stn.fazenda.gov.br/Premio_TN/conteudo_mono_pr1_tema13.htlm>. Acesso em: 5 maio 2003.

OLIVEIRA, L. C. S. Auditoria operacional sob a ótica da eficácia - a relevância da sua utilização pelo sistema de controle interno federal. Disponivel em: <www.milenio.com.br/siqueira/tr018.htm>. Acesso em: 15 abr. 2003.

PARAÍBA. Secretaria do Controle da Despesa Pública. Programa de Modernização do Controle Interno: Promocin. João Pessoa: 1999. 109p. RIBEIRO, S. M. R. Controle interno e paradigma gerencial. Brasilia, DF: Mare/Enap, 1997. (Texto para discussão n. 17).

SILVA, F. C. C. Controle e reforma administrativa no Brasil. 1999. 90f. Dissertação (Mestrado em Administração) - Núcleo de PósGraduação em Administração, Universidade Federal da Bahia, Salvador, 1999.

SILVA, L. M. Controladoria Pública - modelo para o controle interno integrado no setor público. Revista Brasileira de Contabilidade, São Paulo, n.95, 1995.

. Contabilidade governamental: um enfoque administrativo. 5. ed. São Paulo: Atlas, 2002. 